\title{
Prevalence and Nature of Child Neglect and Mental Health Status of Secondary School Adolescents
}

\author{
Akpunne Bede C. \\ Department of Behavioural Studies, \\ College of Management Sciences, \\ Redeemer's University \\ Osun State, Nigeria.
}

\begin{abstract}
Child neglect results in some forms of physical, and mental illness. Research on child neglect and mental health status of Nigerian secondary school adolescents is scanty. A purposive sample of 280 senior secondary school adolescents from two Local Government Areas of Ogun State responded to Neglect Scale (NS) (Form A20) and General Health Questionnaire (GHQ-12). Both descriptive and inferential statistics were employed in the data analysis. The prevalence rate of child neglect among the adolescents ranges from $\mathbf{4 9 . 5 \%}$ (total child neglect) to $\mathbf{7 4 . 2 \%}$ (physical neglect). The prevalence rate of poor mental health was $35.4 \%$.There was no significant sex difference in both child neglect and mental health status of the adolescents. Significant positive correlation was observed between child neglect and poor mental health status. Parental occupation and family size significantly influenced both child neglect and mental health status of adolescents. There was a high prevalence of child neglect and poor mental health among the adolescents. Family size and parental occupations were significant determinants of poor mental health. Secondary school curriculum should include acceptable practices in parenthood, policies on child neglect should be effectively enforced, and more research efforts on child neglect should be carried out.
\end{abstract}

Keywords: child neglect, mental health, school adolescents, Nigeria.

\section{INTRODUCTION}

Child abuse and neglect has long been reported in literature. Records of infanticide, mutilation, abandonment and other forms of violence against children dates back to ancient civilisation (Ten-Bensel, et al 1997). There are historical records with reports of unkempt, weak and malnourished children cast out by families to fend for themselves and of children who have been sexually abused (World Health Organisation, (WHO) 2006). A global conceptualisation of child abuse and neglect should take into cognisance the differing culture of the societies as this defines how people are expected to conduct themselves. The culture of a society influences and defines the generally accepted principles of child-rearing and child care. Some researchers suggests that due to the divergent cultural perspectives on childrearing, reaching a generally accepted definition on what practices are abusive or neglectful may be extremely difficult to reach (National Research Council 1993; Facchin et al, 1998). There is no generally accepted definition of child abuse as a result of differences in the perception of what generally is acceptable as abusive or not. The African Network for Prevention and Protection Against Child Abuse and Neglect (ANPPCAN, 2000) defines child abuse as "the intentional, unintentional or well intentional acts which endanger the physical health, emotional, moral and the educational welfare of children. According to WHO (2014) child maltreatment is the abuse and neglect that occurs to children under 18 years of age. It includes all types of physical and/or emotional illtreatment, sexual abuse, neglect, negligence and commercial or other exploitation, which 
results in actual or potential harm to the child's health, survival, development or dignity in the context of a relationship of responsibility, trust or power. Exposure to intimate partner violence is also sometimes included as a form of child maltreatment.

The US Federal Child Abuse Prevention and Treatment Act (CAPTA, 2010), defines child abuse and neglect as, at minimum any recent act or failure to act on the part of a parent or caretaker which results in death, serious physical or emotional harm, sexual abuse or exploitation; or an act or failure to act which presents an imminent risk of serious harm. According to Bovarnick, (2007) child neglect is a form of child maltreatment, a deficit in meeting a child's basic needs including the failure to provide basic physical, health care, supervision, nutrition, emotional, education and/or safe housing needs. In a similar view Hildyard\& Wolfe, (2002) affirms that neglect often implies a chronic lack of parent care and comfort. In turn, this lack of care poses a significant threat to the welfare and development of young children.

Child maltreatment can be seen as any act of omission or commission, physical or psychological mistreatment or neglect of a child by its parents, guardians, caregiver or other adults that may endanger the child's physical, psychological or emotional health and development. In this definition, wrongfully maltreating a child or selfishly making an unfair use of a child's services by adults responsible for the child constitutes child abuse. Thus the adult may not be directly related to the child but a person in whose care the child is left can be an abuser. This may include the educators, healthcare workers, day care workers, or other responsible adults (National Child Abuse and Neglect Data System (NCANDS), 2012; CAPTA, 2012; Child Welfare Information Gateway, 2013).

\section{Conceptualising Child Neglect.}

Due to variety of definitions of what constitutes neglect and coupled with the fact that laws on reporting abuse do not always require the mandatory reporting of neglect, it is difficult to estimate the global dimensions of the problem or meaningfully to compare rates between countries. Little research, for instance, has been done on how children and parents or other caregivers may differ in defining neglect. Neglect refers to the failure of a parent to provide for the development of the child - where the parent is in a position to do so - in one or more of the following areas: health, education, emotional development, nutrition, shelter and safe living conditions. Neglect is thus distinguished from circumstances of poverty in that neglect can occur only in cases where reasonable resources are available to the family or caregiver. The parents of neglected children are not necessarily poor. They may equally be financially well-off. Many researchers include neglect or harm caused by a lack of care on the part of parents or other caregivers as part of the definition of abuse (Wolfe, 1999; ANPPCAN, 2000; Menick, 2001; Child Welfare Information Gateway 2013).

Child neglect takes many forms: physical, emotional, intellectual, social, moral and educational neglect. Physical neglect involves parents' or caregiver's failure to provide enough food or proper diet, adequate clothing, health care, shelter or sanitary conditions in the home and personal hygiene which could result in stunted growth, malnutrition and vitamin deficiencies (Olukoshi, 1990). Neglected children include those who experience any or all of these: being left alone in the house or in the streets for long periods of time, Lack of parental support, or being snubbed when distressed or even excited or happy or having no health care when required or no chance to have fun with their parents or with other children in their neighbourhood. Of all forms of maltreatment, neglect leads to some of the most thoughtful negative and lasting effect on brain and other physical development, behavioural, educational, achievement and emotional well-being of adolescents. 
Statistics indicate that neglect has a higher prevalence rate than other forms of childhood maltreatment such as physical or sexual abuse (Harrington, Zuravin, DePanfilis \& Ting 2002). Cawson et al (2000) found that 18 percent of a random sample of 18 to 24 year olds reported some absence of care in childhood, and 20 percent had experienced inadequate supervision. Bifulco \& Moran (1998) reported a 17\% rate for moderate to severe neglect of 17 percent. In Kenya, abandonment and neglect were the most commonly cited aspects of child abuse when adults in the community were questioned on the subject (ANPPCAN, 2000). 21.9\% of children reported that they had been neglected by their parents in Kenya. In Canada, a national study of cases reported to child welfare services found that, among the substantiated cases of neglect, $19 \%$ involved physical neglect, $12 \%$ abandonment, $11 \%$ educational neglect, and $48 \%$ physical harm resulting from a parent's failure to provide adequate supervision (Troeme', \& Wolfe, 2001).

Data from the 1998 National Child Abuse and Neglect Data System (NCANDS) (Department of Health and Human Services [DHHS], 2012), based on official reports for child abuse and neglect, reveal that more than twice as many children reported to Child Protective Service (Child Welfare Information Gateway, 2014) agencies were neglected. In addition, the Third National Incidence Study of Child Abuse and Neglect (NIS-3) (DHHS, 1996) found that more neglected children suffered harmful consequences: 879,000 children met the harm standard for neglect whereas fewer than half met the same standard for physical abuse $(381,700)$, and less than a quarter met it for sexual $(217,700)$ and emotional abuse $(204,500)$. As in prior years, the greatest percentage of children suffered from neglect. Child Welfare Information Gateway (2014) investigations returned that more than 75 percent suffered neglect, more than 15 percent suffered physical abuse, and fewer than 10 percent suffered sexual abuse.

\section{The Prevalence of Child Neglect in Nigeria.}

Studies returned high prevalence rates of child neglect in Nigeria. Amuchie \& Ogbonnaya, (2006) argued that the Nigerian society (policy makers, parents, guardians, care-takers, foster parents, teachers and trainers) still trample upon the rights of the child at home, in the school and in the community. Olawale (1995) and Obidigbo (1999) described child abuse and neglect as intentional, unintentional and / or well-intentional acts, which endanger the physical, health emotional, moral and educational welfare of the child. Olawale (1995), Kalu (1996) and Obidigbo (1999) distinguished between child abuse and neglect. While child abuse consists of acts developed or commissioned to inflict harm directly or indirectly on a child, child neglect involves disregard to general needs of the child, which interfere with his / her welfare and development. This means that any abusive or neglectful act or deed meted on any person under the age of eighteen is regarded as child abuse and neglect.

The Nigerian society records a high incidence of child labour, child maltreatment, child marriage, child trafficking, neglect, and child prostitution. The effect of such abuses are many and varied including teenage pregnancies/mothers, youth restiveness and violence, cultism, youth decadence, joblessness, armed bandits, molestations, and school dropouts. These menaces have eaten into the life of most Nigerian children (Umobong 2012).

According to Ebigbo (1990) many parents put their own needs as priorities before those of their children. Umobong (2012) states that parents push over the responsibility of caring for their children to the school. Thus many young children who would have been at home at about two years have been pushed over to the school. The tasks thus become enormous for the teachers and the school management to carry leading to many children being neglected, despised and abused on a daily basis. Madubuko (1989), reports that children from both sexes in secondary schools were abused. In Nigeria child mortality rates by age one is 109 out of 
1000 live births, while 217 die before the age of five. Over six million children are not in school; fifteen million children are working, out of which two million works for up to fifteen hours or more per day (Ebigbo, 2003). Madubuko (1989) reported that neglected children in Enugu wore torn clothes, torn shoes, were often hungry, had no pocket money, and trekked long distance to school. The above indicators reveal a high prevalence rate of child neglect in Nigeria.

\section{Consequences of Neglect on Adolescents' Mental Health.}

Mental health describes the level of psychological wellbeing of an individual. Due to cultural differences, subjective assessment and competing professional theories, WHO (2001, 2010) declares that there is no official definition of mental health. Hence what constitute mental health is socially constructed and defined. WHO (2010) however defines mental health as "a state of well-bring in which the individual realizes his or her own abilities, can cope with the normal stresses of life, can work productively and fruitfully, and is able to make a contribution to his or her community". About one fifth of the global population is comprised of youth between the ages of 14-24. 85-90 per cent of this group live in low-resource countries (Fisher \& Cabral de Mello, 2011; Sawyer et al, 2012). About 5 per cent of youths in high resource countries have a serious mental illness. On a global level, it is estimated that approximately 20 per cent of youth (well over one billion youth), experience a mental-health condition each year (Patel, Flisher \& others, 2007; United Nations Children's Fund, 2012). According to Kessler et al, (2005), adolesents are at the greatest risk of a range of mental-health conditions during their transition from childhood to adulthood due to the host of physical, psychological and emotional changes which occur during this stage of life. Epidemiological research suggests that the majority of individuals with mental-health conditions first experience symptoms prior to age 24 (Kessler et al, 2005). Studies from low- and middle-income countries report similar prevalence estimates of youth mental health status (Kieling et al, 2011). Mental-health conditions negatively impact youths' development, quality of life and ability to fully participate in their communities (Fisher \& Cabral de Mello, 2011).

Suicide is the fifth highest cause of death among youths globally and second highest in highincome countries (WHO, 2003; Blum \& Nelson-Mmari, 2004). Among youth between the ages of 15-24, 17 per cent of all disability adjusted life years are due to mental and behavioral disorders, with an additional 4.5 per cent due to self-harm and 5 per cent due to other neurological disorders (Murray et al, 2012). Adolescent depression often continues unabated into adulthood (Dunn \& Goodyear, 2006). WHO (2007) declared that 20\% Nigerians suffer mental illness. However, Owoyemi, (2013) reports that about 64 million Nigerians suffer from mental illness. This implies that the burden of poor mental health in Nigeria is on the increase. Approximately one in five children suffers from a mental disorder (WHO, 2005; Kelleher, 2004).

The health and social consequences of child abuse and neglect include major harm to the physical and mental health and development of victims. Studies have indicated that exposure to maltreatment and other forms of violence during childhood is associated with risk factors and risk-taking behaviours later in life. These include violent victimization and the perpetration of violence, depression, smoking, obesity, high-risk sexual behaviours, unintended pregnancy, and alcohol and drug use which can lead to diseases such as heart disease, sexually transmitted diseases, cancer suicide, death, and disability. Child neglect therefore contributes to a broad range of adverse physical and mental health outcomes that are costly, both to the child and to society, over the course of a victim's life. Neglect is extremely damaging to children in the short and long term. The experience of childhood neglect affects 
physical, cognitive and emotional development, friendship, behavioural and opportunities of adolescent.

Child neglect results in some forms of ill health. Researchers have studied some of the general health consequences of child maltreatment (Kotch, 1993; Bendixen, Muss \&, Schei, 1994; Briere, 1994; Bifulco \& Moran, 1998; Briere, 1992; Lau, et al, 1999, WHO, 2010; NCANDS, 2012; Child Welfare Information Gateway, 2013), others focused on psychiatric disorders and suicidal behaviour (Fergusson, Horwood, \& Lynskey, 1996; Wolfe, 1999; NCANDS, 2012; Child Welfare Information Gateway, 2014). There are also evidences that some major adult forms of illness such as ischaemic heart disease, cancer, chronic lung disease, irritable bowel syndrome and fibromyalgia, are related to experiences of abuse during childhood (Felitti, et al, 1998; Anda, 1999; McBeth, et al 1999). This explains why abused and neglected children adopt risky behaviour associated with adults such as smoking, alcohol abuse, poor diet and lack of exercise. Researchers have also highlighted important direct acute and long-term consequences of child neglect (Kotch, 1993; Felitti et al, 1998; Anda, 1999; McBeth, et al 1999; Alexander, Levitt \& Smith, 2001; Cooperman \&, Merten, 2001; Child Welfare Information Gateway, 2014).

Similarly, there are many studies that reveal the short-term and long-term psychological damage of child abuse and neglect. Some neglected children have serious psychiatric symptoms, such as depression, anxiety, substance abuse, aggression, shame or cognitive impairments, PTSD, and sleep disorder (Bendixen, Muss \&, Schei, 1994; Fergusson, et al., 1996; Choquet, et al, 1997; Bifulco \& Moran, 1998; Wolfe, 1999,; Child Welfare Information Gateway, 2011, 2014). Neglected children often have language delays, have difficulty maintaining positive self-esteem and are often socially isolated. They tend to be withdrawn passive and apathetic in their approach to life, have trouble understanding complex messages due to poor communication skills. They are often more socially detached and more disinterested (Crittenden, 1992), are more likely to be perplexed by the emotional cues of others and less able to differentiate emotions (Pollack, Cichetti, Harnung \& Reed 2000). Physical, behavioural and emotional manifestations of abuse and neglect vary between children, depending on the child's stage of development when the abuse occurs, the severity of the abuse, the relationship of the perpetrator to the child, the length of time over which the abuse and neglect continues and other factors in the child's environment (National Research Council, 1993; Alexander, et al., 2001, Briere 1992; McBeth, 1999; Child Welfare Information Gateway, 2011, 2014).

While studies in most advanced countries return a decrease in other forms of maltreatment, they show a significant increase in the rate of child neglect (CAPTA 2012; Child Welfare Information Gateway, 2014). In Nigeria the problem of child neglect have not received adequate study despite the apparent perpetration of the act in our society. Similarly the extent to which child neglect influence the mental health status of adolescent is scarce in literature.

\section{Objectives}

1. To find out the prevalence and nature of child neglect and poor mental health status among secondary school adolescent students of Ogun state Nigeria

2. To find out the gender difference in child neglect and mental health status secondary school adolescent students of Ogun state Nigeria

3. To determine the relationship between child neglect and poor mental health status secondary school adolescent students of Ogun state Nigeria

4. To ascertain the influence of parental occupation on child neglect and poor mental health status of secondary school adolescents students of Ogun state Nigeria 
5. To ascertain the influence of family size on child neglect and poor mental health status of secondary school adolescents students of Ogun state Nigeria

\section{Research Questions}

1. What is the prevalence and nature of child neglect and poor mental health status among secondary school adolescent students of Ogun state Nigeria?

2. What is the gender difference in child neglect and mental health status secondary school adolescent students of Ogun state Nigeria?

3. What is the relationship between child neglect and poor mental health status of secondary school adolescent students of Ogun state Nigeria?

4. What is the influence to parental occupation on child neglect and poor mental health status of secondary school adolescent students of Ogun state Nigeria?

5. What is the influence of family size on child neglect and poor mental health status of secondary school adolescent students of Ogun state Nigeria?

\section{METHODOLOGY}

A cross sectional survey design was employed in the study. The population comprised of secondary school adolescents. A purposive sampling technique was adopted to select 280 adolescents from four senior secondary school in Obafemi-Owode and Sagamu Local Government Areas of Ogun state Nigeria who participated in the study.

\section{Instruments}

Two research instruments were used in this study. These are the Neglect Scale (NS) (Form A20) with Reliability coefficient (Alpha $=.89$ ) by Straus, Kinard \& Williams (1979) and General Health Questionnaire (GHQ-12) (Goldberg, 1970).

\section{Data analysis and presentation.}

The data was analysed using SPSS package, such as simple percentage, $t$-test for independent groups and Pearson moment correlation analysis.

RESULTS

Table 1. Prevalence of child neglect and poor mental health status among senior secondary school adolescent

\begin{tabular}{|l|l|l|}
\hline \multicolumn{2}{|l|}{ Variables } & Prevalence \\
\hline Nature of Child Neglect & Emotional neglect & $60.9 \%$ \\
\cline { 2 - 3 } & Physical neglect & $74.2 \%$ \\
\cline { 2 - 3 } & Cognitive neglect & $59.5 \%$ \\
\cline { 2 - 3 } & Supervision neglect & $62.1 \%$ \\
\cline { 2 - 3 } & General child Neglect & $49.5 \%$ \\
\hline Poor Mental Health & $35.4 \%$ \\
\hline
\end{tabular}

Table 1 returned a prevalence rate of $49.5 \%$ for child neglect which includes emotional neglect (60.9\%), physically neglected (74.2\%), cognitive neglect (59.5\%), supervision neglect (62.1\%), and general child neglect (49.5\%). The prevalence of poor mental health status was among the adolescents was $35.4 \%$.

Table 2: Gender difference on child neglect and mental health status of senior secondary school adolescents. 


\begin{tabular}{|l|l|l|l|l|l|}
\hline Nature of Child Neglect & Gender & $\mathbf{N}$ & Mean & $\mathbf{t}$ & $\mathbf{p}$ \\
\hline \multirow{3}{*}{ Emotional neglect } & Male & 130 & 16.08 & .573 & $>0.05$ \\
\cline { 2 - 5 } & female & 148 & 15.58 & & \\
\hline Supervision neglect & Male & 130 & 16.81 & .745 & $>0.05$ \\
\cline { 2 - 5 } & female & 148 & 15.54 & & \\
\hline Cognitive neglect & Male & 130 & 14.32 & -.076 & $>0.05$ \\
\cline { 2 - 4 } & female & 148 & 14.35 & & \\
\hline Physical neglect & Male & 130 & 16.75 & .066 & $>0.05$ \\
\cline { 2 - 4 } & female & 148 & 15.72 & & \\
\hline General child neglect & Male & 130 & 58.74 & 1.69 & $>0.05$ \\
\cline { 2 - 4 } & female & 148 & 55.74 & & \\
\hline Mental health & Male & 130 & 14.90 & 1.88 & $>0.05$ \\
\cline { 2 - 4 } & female & 148 & 14.15 & & \\
\hline
\end{tabular}

Table 2 returned no significant gender difference on nature of child neglect and mental health status of senior secondary school adolescents in Ogun state, Nigeria. This implies that both male and female senior secondary school students were subjected to similar treatment by their various caregivers. However the mean score for the male students was consistently higher than that of the female students, which suggests that male probable suffered more child neglect from caregivers and poorer mental health status than the female adolescent students.

Table 3: Correlation analysis between child neglect and mental health status of senior secondary school adolescents

\begin{tabular}{|l|l|c|c|}
\hline \multicolumn{1}{|c|}{ Nature of child Neglect } & \multicolumn{1}{c|}{ N } & r & p \\
\hline Emotional neglect & 280 & .948 & $<0.05$ \\
\hline Physical neglect & 280 & .958 & $<0.05$ \\
\hline Cognitive neglect & 280 & .944 & $<0.05$ \\
\hline Supervision neglect & 280 & .910 & $<0.05$ \\
\hline General child Neglect & 280 & .993 & $<0.05$ \\
\hline
\end{tabular}

Table 3 returned significant positive correlation between poor mental health status and emotional neglect $(\operatorname{rxy}(280)=.984, \mathrm{p}<0.05)$, physical neglect $(\operatorname{rxy}(280)=.958, p<0.05)$, cognitive neglect $(\operatorname{rxy}(280)=.944, \mathrm{p}<0.05)$, supervision neglect $(\operatorname{rxy}(280)=.910, p<0.05)$ and general child neglect $(\operatorname{rxy}(280)=.933, \mathrm{p}<0.05)$. This shows that the degree of care shown to a child by a care giver has significant influence on the mental health status of a child.

Table 4: Father's occupation difference on child neglect and mental health status of senior secondary school adolescents.

\begin{tabular}{|l|l|l|l|l|l|}
\hline Variables & Father's Occupation & Mean & N & t & p \\
\hline Emotional neglect & Formal & 14.11 & 103 & -2.03 & $<0.05$ \\
\cline { 2 - 4 } & Non- Formal & 15.98 & 164 & & \\
\hline
\end{tabular}


C, A. B. (2015). Prevalence and Nature of Child Neglect and Mental Health Status of Secondary School Adolescents. Advances in Social Sciences Research Journal, 2(4) 233-247.

\begin{tabular}{|l|l|l|l|l|l|}
\hline \multirow{3}{*}{ Physical Neglect } & Formal & 13.95 & 103 & -2.15 & $<0.05$ \\
\cline { 2 - 4 } & Non- Formal & 14.87 & 164 & & \\
\hline Cognitive neglect & Formal & 13.92 & 103 & -2.19 & $>0.05$ \\
\cline { 2 - 4 } & Non- Formal & 14.71 & 164 & & \\
\hline Supervision Neglect & Formal & 14.01 & 103 & -2.14 & $<0.05$ \\
\cline { 2 - 4 } & Non- Formal & 14.92 & 164 & & \\
\hline General Child Neglect & Formal & 54.89 & 103 & -1.96 & $<0.05$ \\
\cline { 2 - 4 } & Non- Formal & 58.48 & 164 & & \\
\hline Mental health & Formal & 13.96 & 103 & -2.13 & $<0.05$ \\
\cline { 2 - 4 } & Non- Formal & 14.83 & 164 & & \\
\hline
\end{tabular}

Table 4 revealed a significant father's occupation difference on emotional neglect, physical neglect, cognitive neglect, supervision neglect general child neglect and mental health status of senior secondary school adolescents. Also those whose fathers' had non-formal occupational consistently returned higher mean score than those whose fathers' had formal occupation. We can therefore conclude that fathers' engaged in non formal vocations neglect their wards more than those with formal vocations.

Table 5: Mother's occupation difference on child neglect and mental health status of senior secondary school adolescents.

\begin{tabular}{|c|c|c|c|c|c|c|}
\hline Variables & $\begin{array}{l}\text { Mother's } \\
\text { Occupation }\end{array}$ & $\mathbf{N}$ & Mean & SD & $\mathbf{t}$ & $\mathbf{p}$ \\
\hline \multirow[t]{2}{*}{ Emotional neglect } & Formal & 79 & 3.582 & .794 & \multirow[t]{2}{*}{5.00} & \multirow[t]{2}{*}{$<0.05$} \\
\hline & Non- Formal & 197 & 2.832 & 1.232 & & \\
\hline \multirow[t]{2}{*}{ Physical Neglect } & Formal & 79 & 8.253 & 4.662 & \multirow[t]{2}{*}{.2 .74} & \multirow[t]{2}{*}{$>0.05$} \\
\hline & Non- Formal & 197 & 6.619 & 4.394 & & \\
\hline \multirow[t]{2}{*}{ Cognitive neglect } & Formal & 79 & 14.949 & 3.915 & \multirow[t]{2}{*}{-1.97} & \multirow[t]{2}{*}{$>0.05$} \\
\hline & Non- Formal & 197 & 15.974 & 3.888 & & \\
\hline \multirow[t]{2}{*}{ Supervision Neglect } & Formal & 79 & 6.632 & 3.147 & \multirow[t]{2}{*}{-.502} & \multirow[t]{2}{*}{$<0.05$} \\
\hline & Non- Formal & 197 & 7.051 & 7.111 & & \\
\hline \multirow{2}{*}{$\begin{array}{ll}\text { General } & \text { Child } \\
\text { Neglect } & \end{array}$} & Formal & 79 & 56.78 & 11.207 & \multirow[t]{2}{*}{-.199} & \multirow[t]{2}{*}{$<0.05$} \\
\hline & Non- Formal & 197 & 57.17 & 16.012 & & \\
\hline \multirow[t]{2}{*}{ Mental health } & Formal & 79 & 14.18 & 2.849 & \multirow[t]{2}{*}{-1.077} & \multirow[t]{2}{*}{$>0.05$} \\
\hline & Non-formal & 197 & 14.61 & 3.453 & & \\
\hline
\end{tabular}

Table 5 revealed a significant mother's occupation difference on emotional neglect, supervision neglect and general child neglect. However no significant mother's occupation difference was observed on physical neglect, cognitive neglect, and mental health status of senior secondary school adolescents. 
Table 6: Correlation analysis between family size and child neglect among senior secondary school adolescents

\begin{tabular}{|l|l|l|}
\hline Nature of neglect & $\mathbf{r}$ & $\mathbf{p}$ \\
\hline Emotional neglect & .090 & $>0.05$ \\
\hline Physical neglect & -.009 & $<0.05$ \\
\hline Cognitive neglect & .080 & $<0.05$ \\
\hline Supervision neglect & .126 & $<0.05$ \\
\hline General child Neglect & .045 & $<0.05$ \\
\hline
\end{tabular}

Table 6 shows a significant positive correlation between family size and physical neglect, cognitive neglect, supervision neglect and general child neglect among senior secondary school adolescent students of Ogun state, Nigeria. This implies that the larger the family size the more the physical, cognitive, supervision and general child neglect.

\section{DISCUSSION}

Findings returned a $35.4 \%$ prevalence of poor mental health status among senior secondary school adolescents. This result shows a high rate of poor mental health among adolescents in Nigeria. This findings support previous research on the high rate of mental health disorder globally. WHO $(2006,2008)$ estimates that about 154 million people suffer from depression, and 25 million people suffer from schizophrenia. Empirical studies also reveal that about 64 million Nigerians manifest psychological disorder (Abiodun, 2006; WHO, 2007; Owoyemi, 2013). Also Study carried out by Storrie, Ahern \& Tuckett, (2010) on mental health problem among youths affirmed that nearly half the world's population is affected by mental illness with an impact on their self-esteem, relationships and ability to function in everyday life. 154 million people suffer from depression and 25 million people from schizophrenia; 91 million people are affected by alcohol use disorders and 15 million by drug use disorders (WHO 2008). As many as 50 million people suffer from epilepsy and 24 million from Alzheimer and other dementias (WHO 2006). Hundreds of thousands of people die by suicide every year (WHO 2003). In a related study Kelleher $(2004)$ and WHO $(2005,2008)$ affirmed that approximately one in five children suffers from a mental disorder.

The study also showed a high prevalence of child neglect among adolescents in Nigeria ranging from $49.5 \%$ (total child neglect) to $74.2 \%$ (physical neglect). Similar studies have been carried out about child abuse and neglect in Nigeria with alarming results. This is in agreement with statistics given by Child Welfare Information Gateway (2014) that nearly $70 \%$ (69.9 percent) of child fatalities were attributed to neglect only or a combination of neglect and another maltreatment type. Ebigbo (1989) observed that many parents put their own needs as priorities before those of their children. Madubuko (1989) reported that children from both sexes in secondary schools were abused. Ebigbo (1990) showed that young girls who are exposed to hawking tend to be lured into enticement, rape and other sexual molestation. According to Danesy \& Busari (2005), sudden death of one or both parents usually results in a child being raised by foster parents with a tendency of devastating effects such as harsh treatment, neglect, battering and hawking. United Nations Children Emergency Fund (UNICEF, 2003) report on child abuse revealed that in Nigeria, child mortality rates by age one is 109 out of 1000 live births, while 217 die before the age of five. Ebigbo (2003) added that over six million children are not in school; fifteen million children are working, out of which two million works for up to fifteen hours or more per day. Madubuko (1989), reported that neglected children in Enugu wore torn clothes, torn shoes, were often hungry, had no pocket money, and trekked long distance to school. 
Furthermore this study returned no significant gender difference on nature of child neglect and mental health status of senior secondary school adolescents in Ogun state, Nigeria. We therefore conclude that both male and female senior secondary school students were subjected to similar treatment by their various caregivers. In related studies Madubuko (1989), reported that children from both sexes in secondary schools were neglected.

This study returned significant positive correlation between emotional, physical, cognitive, supervision and general child neglect and poor mental health status. Related research indicated an association between neglect and health problems in children and adolescents (Flalorty, et al., 2006, 2009). A study by Hussey, Chang \& Kotch (2006) found that all types of neglect were associated with 8 of 10 adolescent health risk and that trauma caused by experiences of child neglect can have serious effects on the developing brain, increasing the risk of psychological problems. There is a strong relationship between child neglect and posttraumatic stress disorder (PTSD), learning difficulties, poor academic achievement, behaviour problems in childhood and adolescent. Maltreated children manifest psychiatric illnesses such as anxiety disorders and sleep disorders (Fergusson, et al, 1996; Wolfe, 1999; Trowell et al, 1999; Schore, 2002; Child Welfare Information Gateway, 2014). Complex trauma affects the developing brain and will interfere with child's capacity to integrate to sensory, emotional and cognitive responses to subsequent stress. Abuse and neglect in the early years of life can seriously affect the developmental capacities of infants especially in the critical areas of speech and language (Wolfe, 2009). Research has indicated that neglected children perform less well on standard tests and achieve poorer school marks, even when socio-economic status and other background factors are taken into account (Child Welfare Information Gateway, 2011, 2014). Hildyard \& Wolfe, (2002), found an association between abuse and neglect with internalising behaviours' (being withdrawn, sad, isolated and depressed) and externalising behaviours (being aggressive or hyper-active) throughout childhood as well as difficulty in making friends. Neglected children also are at risk for repeating the neglected behaviour with their own children. Suicidal thoughts occur most during adolescence (Blum \& Nelson-Mmari, 2004). Eating disorders including anorexia and binge-purge behaviour (bulimia), may also be associated with child abuse and neglect.

A significant father's occupation difference on emotional neglect, physical neglect, cognitive neglect, supervision neglect general child neglect and mental health status of senior secondary school adolescents was observed. Also those whose fathers' had non-formal occupational consistently returned higher mean score than those whose fathers' had formal occupation. Fathers' engaged in non formal vocations neglect their wards more than those with formal vocations.

Finally, a significant positive correlation was revealed between family size and physical neglect, cognitive neglect, supervision neglect and general child neglect among senior secondary school adolescent. This finding is consistent with previous researches which returned association between neglect and large family size. Large family size is seen as a powerful predictor of neglect especially for very low-income, single-parent families. Larger numbers of children in low income families increase degree of child neglect (Andry, 1971,; Olawale, 1995,; Obidigbo, 1999). In most large families especially polygamous homes, children are left to fend for themselves. The size of the family can also increase the risk for abuse and neglect. A study of parents in Chile, for example, found that families with four or more children were three times more likely to be violent towards their children than parents with fewer children (Larrain, Vega, \&Delgado, 1997).However, it is not always simply the size of the family 
that matters. Data from a range of countries indicate that household overcrowding increases the risk of child abuse (Youssef, Attia \& Kamel, 1998; Kim et al 2000; Sumba \& Bwibo, 1993; Tadele, Tefera \& Nasir,1999; Dubowitz \& Black, 2001; Isaranurug, et al, 2001). Unstable family environments, in which the composition of the household frequently changes as family members and others move in and out, are a feature particularly noted in cases of chronic neglect (National Research Council, 1993; \& Black, 2001).

\section{CONCLUSION}

There is a high prevalence rate of child neglect among senior secondary school adolescents in Nigeria which ranges from $49.5 \%$ (total child neglect) to $74.2 \%$ (physical neglect) also the prevalence rate of poor mental health among the participants was $35.4 \%$. No significant gender difference was observed on nature of child neglect and mental health status of senior secondary school adolescents in Ogun state, Nigeria.

Significant positive correlation exists between emotional neglect, physical neglect, cognitive neglect, supervision neglect and general child neglect and poor mental health status.

There is a significant father's occupation influence on emotional neglect, physical neglect, cognitive neglect, supervision neglect general child neglect and mental health status of senior secondary school adolescents. Adolescents whose fathers' had non-formal occupational consistently returned higher mean score than those whose fathers' had formal occupation. This is suggestive that fathers' engaged in non formal vocations neglect their wards more than those with formal vocations. Similarly, mother's occupation influence was observed on emotional neglect, supervision neglect and general child neglect. However no significant mother's occupation difference was observed on physical neglect, cognitive neglect, and mental health status of senior secondary school adolescents. Finally, there is a significant positive correlation between family size and physical neglect, cognitive neglect, supervision neglect and general child neglect among senior secondary school adolescent students..

\section{RECOMMENDATION}

Among others things there is need to develop effective intervention programmes that will improve parenting practices and provide family support.

Also the Nigerian education ministry should create programmes and secondary school curriculum focused on training adolescents on "acts - of - parenting". Such programmes would educate adolescents (would-be parents) on preparation for parenthood, understanding child development, help them improve their skills in managing children's behaviour and subsequently reduce the rate of child neglect.

Furthermore, policies on what constitute child neglect, and its attendant consequences on the child the family and the society should be promulgated and widely publicized and enforced. Also through the social work and social welfare services families and caregivers that violate the child rights especially in the area of abuse and neglect should be identified and sanctioned, and appropriate intervention programmes planned.

There is need for a widespread prevention and education campaign to stem the problem of child neglect in Nigeria. The goal of such campaign would be to increase public awareness of child neglect, its victims and perpetrators. The campaign could include televised documentaries, short films and commercials, radio programmes, jingles and printed materials such as posters, stickers, booklets and newspaper articles. Regional training sessions should be provided for parents, teachers and child caregivers. Hence through the news media, 
conferences, religious gatherings and other public places the Nigerian society should be educated on what constitute child neglect and the attendant consequences such practices on the child the family the community and the society at large. Finally, there is need for more research attention on the consequences of child neglect on the psycho social health of the Nigerian child.

\section{References}

1. Abiodun, 0. A. (2006). Postnatal depression in primary care populations in Nigeria. General Hospital Psychiatry, 28:133-136.

2. Alexander, R.C., Levitt, C.J., \& Smith, W.L. (2001). Abusive head trauma. In: Reece, R.M., Ludwig, S., (Eds.) Child abuse: medical diagnosis and management, 2nd ed. Philadelphia, PA, Lippincott Williams \& Wilkins, 47-80.

3. Anda, R., et al. (1999). Adverse childhood experiences and smoking during adolescence and adulthood. Journal of the American Medical Association, 282:1652-1658.

4. ANPPCAN. (2000) Awareness and views regarding child abuse and child rights in selected communities in Kenya. Nairobi, African Network for the Prevention and Protection against Child Abuse and Neglect.

5. Bendixen, M., Muss, K.M., \& Schei, B. (1994). The impact of child sexual abuse: a study of a random sample of Norwegian students. Child Abuse \& Neglect, 18:837-847.

6. Bifulco, A. \& Moran, P. (1998). Wednesday's child: research into women's experience of neglect and abuse in childhood, and adult depression, London: Routledge

7. Blum, R. W. \& Nelson-Mmari, K. (2004). The health of young people in a global context. Journal of Adolescent Health, vol. 35, pp. 402-418.

8. Bovarnick, S. (2007). Child neglect. NSPCC child protection research briefing

9. Briere, J.N. (1992). Child Abuse trauma: theory and treatment of the lasting effects (Interpersonal violence: the practice series) Sage Publications, Newbury Park, London, 1992.

10. Briere, J.N.,\& Elliott, D.M. (1994). Immediate and long-termimpacts of child sexual abuse. The Future of Children, 1994, 4:54-69.

11. Bross, D.C., et al. (2000). World perspectives on child abuse: the fourth international resource book. Denver, CO, Kempe Children's Center, University of Colorado School of Medicine.

12. Cawson, P., Wattam, C., Brooker, S. \& Kelly, G. (2000) Child Maltreatment in the United Kingdom: A Study of the Prevalence of Child Abuse and Neglect, London: NSPCC

13. Child Help USA. (2012). Child Abuse Prevention: National Child Abuse Hotline. Online Available: http//www.childabuse. com,.

14. Child Welfare Information Gateway. (2011). About CAPTA: A legislative history. Washington, D C: U.S. Department of Health and Human Services, Children's Bureau.

15. Child Welfare Information Gateway. (2013). What is child abuse and neglect? Recognizing the signs and symptoms. Washington, DC: U.S. Department of Health and Human Services, Children's Bureau

16. Child Welfare Information Gateway. (2014). Child maltreatment 2012: Summary of key findings. Washington, DC: U.S. Department of Health and Human Services, Children's Bureau.

17. Choquet, M., et al. (1997). Self-reported health and behavioural problems among adolescent victims of rape in France: results of a cross-sectional survey. Child Abuse \& Neglect. 21:823-832.

18. Cooperman, D.,R., \& Merten, D.,F. (2001). Skeletal manifestations of child abuse. In: Reece R.M., Ludwig, S., (Eds.) Child abuse: medical diagnosis and management, 2nd ed. Philadelphia, PA, Lippincott Williams \& Wilkins,123-156.

19. Crittenden, P., M. (1992). Children's strategies for coping with adverse home environments: an interpretation using attachment theory. Child Abuse \& Neglect, 16, 329-343.

20. Danesy, A.H \& Busari, A.O. (2005). The nature cause, emotional effects and prevention of child abuse. In A.O. Moronkola (Eds), Contemporary Issues and Researches on Child Abuse. Ibadan: Royal People Nigeria Ltd. 
21. Dubowitz, H., \& Black, M.B. (2001). Child neglect. In: Reece, R. M., \& Ludwig, S., (Eds.) Child abuse: medical diagnosis and management, 2nd ed. Philadelphia, PA, Lippincott Williams \& Wilkins,339-362.

22. Dunn, V., \& Goodyear, I.M. (2006). Longitudinal investigation into childhood and adolescence-onset depression: psychiatric outcome in early adulthood. British Journal of Psychiatry, 188:216-222.

23. Ebigbo, P.O. (1989). Psychosocial aspects of child abuse and neglect in Africa.

24. Ebigbo P.O. (1990). The problems of child abuse and neglect in Nigeria and strategies.

25. For overcoming them. In Adebayo et al (Eds). The Nigeria child Now and in the future. Lagos: Laritex Printing Press.

26. Ebigbo, P.O. (2003). Street Children: The Core of Child Abuse and Neglect in Nigeria. Children, Youth and Environments 13(1), Spring 2003. Retrieved [date] from http://cye.colorado.edu.

27. Facchin P. et al. (1998). European strategies on child protection: preliminary report. Padua, Epidemiology and Community Medicine Unit, University of Padua.

28. Felitti V et al. (1998). Relationship of childhood abuse and household dysfunction to many of the leading causes of death in adults. American Journal of Preventive Medicine, 1998, 14:245-258.

29. Fergusson, D.M., Horwood, M.T. \& Lynskey, L.J. (1996). Childhood sexual abuse and psychiatric disorder in young adulthood. II: Psychiatric outcomes of childhood sexual abuse. Journal of the American Academy of Child and Adolescent Psychiatry; 35:1365-1374.

30. Fisher, J. R. W. \& Cabral de Mello, M. (2011). Using the World Health Organization's 4S Framework to strengthen national strategies, policies and services to address mental health problems in adolescents in resource-constrained settings. International Journal of Mental Health Systems, vol. 5, No. 23.

31. Harrington, D., Zuravin, S., DePanfilis, D., \& Ting, L. (2002). The neglect scale: confirmatory factor analyses in a low-income sample. Child maltreatment, Vol. 7, No. 4, November 2002 359-368 DOI:

10.1177/107755902237266. 7th International Family Violence Research Conference, July 22-25, 2001, held in Portsmouth. Sage Publications

32. Hildyard, C., \& Wolfe, D. (2002). Child Neglect: Developmental Issues and Outcomes, Child Abuse and Neglect, Vol. 26: 679-95

33. Hussy, J., Chang, J., \& Kotch, J. (2006). Child Maltreatment in the United States: prevalence, risk factors and adolescent health consequences. Paediatrics, 118(3), 933-942.

34. Isaranurug, S. et al. (2001). Factors relating to the aggressive behavior of primary caregiver toward a child. Journal of the Medical Association of Thailand , 84:1481-1489.

35. Kelleher K. (2004). Prevention and intervention in primary care. In: Remschmidt H, Belfer M, Goodyear I, (Eds.) Facilitating pathways: care, treatment and prevention in child and adolescent mental health. Berlin, Springer-Verlag.

36. Kessler, R., Berglund, P., Demler, O., Jin, R. \& Walters, E. E. (2005). Lifetime prevalence and age-of-onset distributions of DSM-IV disorders in the National Comorbidity Survey Replication. Archive of General Psychiatry, vol. 62, pp. 593-602.

37. Ketsela T, \& Kedebe, D. (1997). Physical punishment of elementary school children in urban and rural communities in Ethiopia. Ethiopian Medical Journal, 1997, 35:23-33.

38. Kotch, J.B. et al. (1993). Morbidity and death due to child abuse in New Zealand. Child Abuse \& Neglect, 17:233-247.

39. Khartri, K. (2004). Child abuse, definition, prevention, types, treatment, maltreatments articles, children's abuse. http://www.umicos.umd.edu/users/sawweb/sawnet/childabuse.html.

40. Kieling, C., Baker-Henningham, H., Belfer, M., Conti, G., Ertem, I., Omigbodun, O., Rahman, A. (2011). Child and adolescent mental health worldwide: evidence for action. The Lancet, vol. 378, No. 9801, pp. 15151525. doi:10.1016/S0140-6736(11)60827-1.

41. Kim, D.H. et al. (2000). Children's experience of violence in China and Korea: a transcultural study. Child Abuse \& Neglect, 24:1163-1173.

42. Larrain. S., Vega. J, (1997). Delgado. I. Relaciones familiaresy maltrato infantil. [Family relations and child abuse.]Santiago, United Nations Children's Fund. 
43. Lau. J.T. et al. (1999). Prevalence and correlates of physical abuse in Hong Kong Chinese adolescents: a population-based approach. Child Abuse \& Neglect,1999, 23:549-557.

44. Madu, S.N. \& Peltzer, K. (2000).Risk factors and child sexual abuse among secondary students in the Northern Province (South Africa). Child Abuse \& Neglect, 24:259-268.

45. Madubuko, G.U. (1989). Child abuse in boarding and non- boarding schools in Anambra state, Nigeria; Paper presented at the ANPCAN conference, Jos, Nigeria.

46. McBeth, J. et al. (1999). The association between tender points, psychological distress, and adverse childhood experiences. Arthritis and Rheumatism, ,42:1397-1404.

47. Menick, D.M. (2001). La proble'matique des enfants victimes d'abus sexuels en Afrique ou l'imbroglio d'un double paradoxe: l'exemple du Cameroun. [The problems of sexually abused children in Africa, or the imbroglio of a twin paradox: the example of Cameroon.] Child Abuse \& Neglect, 25:109-121.

48. Murray, C. J. L., Vos, T., Lozano, R., Naghavi, M., Lopez, A. D. (2012). Disability-adjusted life years (DALYs) for 291 diseases and injuries in 21 regions, 1990-2010: a systematic analysis for the Global Burden of Disease Study 2010. The Lancet, vol. 380, pp. 2197- 2223.

49. National clearinghouse on Child Abuse and Neglect Information(2006). Child abuse and neglect prevention. Retrieved fromhttp://nccanch.acf.hhs.gov.

50. National Research Council. Understanding childabuse and neglect. (1993)Washington, DC, National Academy of Sciences Press,.

51. Obidigbo, G.C.E. (1999). The prevalence of child abuse and neglect in our society: a case Study of teachers in Enugu state of Nigeria. Ife Psychologia, 7,2, 96-110

52. Olukoshi, A.O. (1990). The child in the contemporary Nigeria: an introduction to issues, Lamirex Printing Press, Lagos,

53. Otensaya, B. (1987). The psycho- social dimension of sexually transmitted disease: a case study of Ahmadu Bello University Teaching hospital', MSc Thesis, Department of Sociology, Ahmadu Bello University, Zaria, Nigeria,.

54. Owoyemi, E. (2013, October 10). Medical experts say 64 million Nigerians suffer from mental illness. Premium Times.

55. Patel, V., A., Flisher J., Hetrick, S. \& McGorry, P. (2007). Mental health of young people: A global publichealth challenge. The Lancet, vol. 369, pp. 1302-1313.

56. Pollack, S.D., Cicchetti, D., Hornumg, K.,\& Reed, A. (2000). Recognizing emotion in faces: developmental effects of child abuse and neglect. Developmental psychology, 679688 dependence, child neglect and domestic violence.

57. Sawyer, S. M., Afifi, R. A., Bearinger, L. H., Blakemore, S. J. Dik, B., Ezeh, A. C. \& Patton, G. C. (2012). Adolescent health 1: Adolescence: a foundation for future health. The Lancet, vol. 379, pp. 1630-1640.

58. Storrie, K; Ahern, K., Tuckett, A. (2010). "A systematic review: Students with mental health problems--a growing problem". International Journal of Nursing Practice, 16(1), 1-6.16 (1): 1-16.

59. Sumba, R.O., Bwibo, N.O. (1993). Child battering in Nairobi, Kenya. East African Medical Journal, 70:688692.

60. Straus, M.S, Kinard, M. \& Williams L. M. (1979). The neglect scale. Family research laboratory, University of New Hampshire Durham, NH03824(603) 862-2594

61. Tadele, G., Tefera, D.\& Nasir, E. (1999). Family violence against children in Addis Ababa. Addis Ababa, African Network for the Prevention of and Protection against Child Abuse and Neglect.

62. Ten-Bensel, R.W., Rheinberger, M.M. \& Radbill S.X. (1997). Children in a world of violence: the roots of child maltreatment. In: Helfer, M.E, Kempe, R.S., \& Krugman R.D. (Eds). The battered child. Chicago, IL, University of Chicago Press,3-28.

63. Troeme', N.H., \& Wolfe, D. (2001). Child maltreatment in Canada: selected results from the Child Canadian Incidence Study of Reported Abuse and Neglect. Ottawa, Minister of Public Works and Government Services Canada. 
64. Trowell, J. et al. (1999). Behavioural psychopathology of child sexual abuse in schoolgirls referred to atertiary centre: a North London study. European Child and Adolescent Psychiatry, 8:107-116.

65. United Nations Children's Fund (2012). Progress for Children: A Report Card on Adolescents (No.10). UNICEF. Available from: http://www.unicef.org/publications/index_62280.html. Accessed on 19 July 2013.

66. United Nations Children's Fund (UNICEF) Nigeria-Fact sheet. Child rights legislation in Nigeria (2013) http://www.unicef.org/nigeria/Child_rights_legislation_in_Nigeria.pdf

67. U.S. Department of Health and Human Services, Administration on Children, Youth, and Families. (2007). Child Maltreatment 2005. Washington, DC: U.S. Government Printing office.

68. WHO, (1999). Report of the Consultation on Child Abuse Prevention, 29-31 March 1999, WHO, Geneva. Geneva, World Health Organization, (document WHO/HSC/PVI/99.1).

69. WHO, (2004). Revised Global Burden of Disease (GBD) 2002 estimates. Geneva, retrieved from World Health Organisation website http://www.who.int/healthinfo/bodgbd2002revised/en/index.html,.

70. WHO, (2006). Neurological disorders: public health challenges. Geneva.

71. Wolfe, D.A. (1999). Child abuse: implications for child development and psychopathology, 2nd ed. Thousand Oaks, CA, Sage,

72. Youssef, R.M., Attia, M.S., \& Kamel, M,I. (1998). Children experiencing violence: parental use of corporal punishment. Child Abuse \& Neglect, ,22:959-973. 